\section{The profiles of packed cells volume, plasma electrolytes and glucose levels in malarial infected patients}

\author{
Saturday Jack Udoh, ${ }^{1}$ \\ Olarinde Olaniran, ${ }^{2}$ Usen Asuquo Udo, ${ }^{1}$ \\ Funmilola Oluyemi Omoya, ${ }^{3}$ \\ Ayodele Josephine Osevwe, ${ }^{1}$ \\ Olufemi Oyewumi Oyetoke, ${ }^{1}$ \\ Babatunde Wumi Odetoyin, ${ }^{2}$ \\ Esther ayobami Awoyeni, ${ }^{2}$ \\ Adeyemi Adesina ${ }^{4}$ \\ ${ }^{1}$ Department of Medical Microbiology \\ and Parasitology, Obafemi Awolowo \\ University Teaching Hospitals Complex, \\ Ile Ife; ${ }^{2}$ Department of Medical \\ Microbiology and Parasitology, Obafemi \\ Awolowo University, Ile-Ife; \\ ${ }^{3}$ Department of Microbiology, Federal \\ University of Technology, Akure; \\ ${ }^{4}$ Department of Chemical Pathology, \\ Obafemi Awolowo University Teaching \\ Hospitals Complex, Ile-Ife, Nigeria
}

\section{Abstract \\ Fifty patients (18 males, 32 females)} with malaria infection and 50 apparently healthy control subjects (22 males, 28 females) were recruited for the study. Hematocrit level (PCV) was determined using Heco $\mathrm{C}$ haematology analyzer. Plasma electrolytes $\left(\mathrm{Na}^{+}, \mathrm{K}^{+}, \mathrm{HCO}_{3}^{-}, \mathrm{Cl}^{-}\right)$, and glucose were respectively analyzed by SM23A Spectrophotometer, using TECO DIAGNOSTICS and RANDOX enzymatic glucose methods respectively. The results showed a significant reduction in the mean values of PCV (30.04 $\pm 5.31 \%), \mathrm{Na}^{+}$ $(131.56 \pm 6.63 \mathrm{mmol} / \mathrm{L})$, and glucose $(85.92 \pm 13.85 \mathrm{mg} / \mathrm{dL})$ in the malaria-infected subjects compared with the mean values of PCV (38.74 $\pm 3.12 \%), \mathrm{Na}^{+}(134.14 \pm 5.95$ $\mathrm{mmol} / \mathrm{L})$, and glucose $(92.40 \pm 13.99$ $\mathrm{mg} / \mathrm{dL})(\mathrm{P}<0.05)$ obtained from the control subjects. We observed higher significant mean values of $\mathrm{K}^{+}(3.93 \pm 0.79 \mathrm{mmol} / \mathrm{L})$ and $\mathrm{HCO}_{3}{ }^{-}(23.56 \pm 2.55 \mathrm{mmol} / \mathrm{L})$ in the malariainfected subjects compared with the control mean values of $\mathrm{K}^{+}(3.62 \pm 0.51 \mathrm{mmol} / \mathrm{L})$ and $\mathrm{HCO}_{3}{ }^{-}(23.48 \pm 2.02 \mathrm{mmol} / \mathrm{L})(\mathrm{P}<0.05)$. The mean values for chloride observed in the malaria-infected subjects, $\mathrm{Cl}^{-}(99.52 \pm 7.44)$ was higher than the observed mean in the control subjects, $\mathrm{Cl}^{-}(99.50 \pm 6.33)$, but was not statistically significant $\mathrm{P}>0.05$. The mean ( \pm standard deviation) of $\mathrm{PCV}, \mathrm{Na}^{+}$, $\mathrm{K}^{+}, \mathrm{HCO}_{3}^{-}, \mathrm{Cl}^{-}$and glucose in malariainfected patients of different age groups were compared with the age-matched controls, and there were significant differences only in the age groups involving PCV and potassium in the 1-20 and $>40$ age brackets. This study has shown the importance of electrolyte management in patients with severe malaria to prevent attendant physiological failure during complications.

\section{Introduction}

Malaria is a tropical disease that occurs in regions lying roughly between latitude $62^{\circ} \mathrm{N}$ and $40^{\circ} \mathrm{S}$ with an altitude of $1500 \mathrm{~m}$. This region falls within the tropics and subtropics and this made malaria endemic in this zone. ${ }^{1}$ The factors that make malaria endemic in the topics include climatic factors (relative humidity altitude, rainfall levels, mean temperature between $18-19^{\circ} \mathrm{C}$ ) and socioeconomic factors. Their interplay determines the two polar epidemiological extremes-stable and unstable malaria. Malaria can be transmitted by three known ways: vector transmission, blood transfusion, and congenital transmission. ${ }^{2}$

Malaria is a life-threatening parasitic disease that is caused by a parasite (Plasmodium) that is transmitted to people through the bites of infected female Anopheles mosquitoes. In 2015, 95 countries and territories had ongoing malaria transmission. About 3.2 billion people about half of the world's populations are at risk of malaria. Malaria is preventable and curable, and increased efforts are dramatically reducing the burden of malaria in many places. Between 2000 and 2015, malaria incidence among populations at risk fell by $37 \%$ worldwide. In that same period, malaria death rates among populations at risk fell by $60 \%$ globally among all age groups, and by $65 \%$ among children under five. Sub-Saharan Africa carries a disproportionately high share of the global malaria burden. In 2015, the region was home to $88 \%$ of malaria cases and $90 \%$ of malaria deaths. Most adults that reside in malariaendemic areas may develop partial immunity which allows asymptomatic infections to occur. ${ }^{3,4}$

Sodium is the major cation of the extracellular fluid and as such plays a central role in the maintenance of the normal distribution of water and osmotic pressure in various fluid compartments. Potassium, on the other hand, is the major intracellular cation having. In addition to water balance, these electrolytes play an important role in the maintenance of $\mathrm{pH}$, regulation of heart and muscle function, electron transfer reactions as well as serving as cofactors for enzymes. A severe malaria infection can lead to con-
Correspondence: Olaniran Olarinde, Department of Medical Microbiology and Parasitology, Obafemi Awolowo University, Ile-Ife, Nigeria.

E-mail: olarinde.olaniran@yahoo.com

Key words: profile, packed cells volume, plasma electrolytes, glucose, malarial.

Contributions: the authors contributed equally.

Conflict of interest: the authors declare no potential conflict of interest.

Received for publication: 16 November 2016. Revision received: 17 March 2017.

Accepted for publication: 30 March 2017

This work is licensed under a Creative Commons Attribution NonCommercial 4.0 License (CC BY-NC 4.0).

(C) Copyright S.J. Udoh et al., 2017

Licensee PAGEPress, Italy

Microbiology Research 2017; 8:6975

doi:10.4081/mr.2017.6975

ditions of electrolyte disturbance such as hyponatraemia, hypernatraemia, hypokalaemia and hyperkalemia. The most pronounced changes related to malaria involve the blood and the blood-forming system, the spleen and the liver. Secondary changes can occur in all the other major organs, depending on the type and severity of the infection. The pathological changes are more profound and severe in the case of Plasmodium falciparum malaria. ${ }^{5}$ Red blood cells are the principal sites of infection in malaria. All other clinical manifestations are primarily due to the involvement of red blood cells. ${ }^{5}$ These can occur in anybody but are more common in severe falciparum malaria, extremes of age and in patients with high degree of fever and vomiting. Nutritional status, hemoglobin type, and erythrocyte glucose-6-phosphate dehydrogenase activity all influence response to malaria infection. Since sodium and potassium have been shown to be highly indispensable in water homeostasis which is fundamental to the survival of all organisms, it is, therefore, necessary to estimate the elves of these electrolytes in all cases of falciparum malaria and in severe malaria cases. ${ }^{6}$ Hypoglycemia is common in malaria, as malaria parasitized red blood cells use glucose 75 times faster than uninfected red blood cells. Several workers have shown that these changes do occur in humans afflicted with malaria, the present study aims at measuring the effect of Plasmodial parasite infection in human subjects by studying the pattern of packed cell volume, plasma electrolytes including sodium, 
potassium, bicarbonate, and chloride as well as glucose levels compared with control human subjects. It is hoped that the outcome will contribute to the effective management of malaria patients affected by these pathological changes.

\section{Materials and Methods}

\section{Study location}

This study was carried out in Ile-Ife, South West of Nigeria located in the rain forest belt of West Africa in the year 2010. This region is noted for malaria parasites endemicity.

\section{Subjects and sample size}

The study subjects were adult males and females as well as children infected with malaria parasites who reported ill with fever (axillary temperature $>37.5^{\circ} \mathrm{C}$ ), headache, vomiting and other clinical signs and symptoms of malaria as documented. One hundred subjects comprising fifty confirmed malaria-infected subjects and fifty apparently healthy individuals (normal controls) between the ages of 5 to 58 years were enrolled in the study. The scope, nature and objective of the investigation were explained to all subjects for their consent which was sought and obtained. All the test subjects that were confirmed as malaria patients were included in the study. Subjects with abnormal sodium, potassium, bicarbonate, chloride electrolyte imbalance), and glucose levels were excluded from the control group.

\section{Sample collection}

Venous blood was collected from the study subjects and dispensed into EDTA bottle, where packed cell volume, electrolytes, and glucose values were estimated.

\section{Microscopic examination of blood films}

The malaria parasite density was determined by examining a thin and thick blood films stained by Giemsa method. The degree of parasitemia was classified as follows:
One parasite per field: low density $(+)$

Two to nine parasites per field: medium density $(++)$

Greater than twenty parasites per field: high density $(+++) .^{2}$

Determination of packed cell volume

Packed cell volume was determined by the $\mathrm{HeCoC}$ three part differentials hematology analyzer (MedWOW, Nicosia, Cyprus).

\section{Plasma sodium estimation}

The method used is based on the modifications of the methods described by Maruna (1958) and Tinder (1951) in which sodium is precipitated as the triple salt, sodium magnesium uranyl acetate, with the excess uranium and reacted with ferrocyanide, producing a chromophore whose absorbance varies inversely as the concentration of sodium in the test specimen. Filtrate preparation was done by labeling test tubes accordingly i.e., blank, standard, control; patient etc. $1.0 \mathrm{~mL}$ of filtrate reagent was Pipetted into all tubes. $50 \mathrm{~mL}$ of the sample was added to all tubes and distilled water to the blank. All tubes were shaken vigorously for three minutes and centrifuged at high speed $(1500 \mathrm{~g})$ for 10 minutes and the supernatant fluids were tested as described by Cheesebrough. ${ }^{2}$ For color development, all the test tubes were labeled in accordance with the labels on the filtrate tubes. Acid reagent $(1.0 \mathrm{~mL})$ was pipetted into all tubes and $50 \mathrm{~mL}$ supernatant was added to the respective tubes and mixed. To each tube, $50 \mathrm{~mL}$ of color reagent was added and mixed. Before use, the spectrophotometer was adjusted to zero with distilled water at $550 \mathrm{~nm}$. The absorbance of all tubes were read and recorded.

\section{Calculation}

Abs. of blank - Abs. of sample

Abs. of blank - Abs. of standard

$\times$ concentration of standard $=$ concentra-

tion of sample in $\mathrm{mmol} / \mathrm{L}$

\section{Expected values $135-155 \mathrm{mmol} / \mathrm{L}$}

\section{Estimation of plasma potassium}

The amount of potassium was estimated by using sodium tetraphenylboron in a specifically prepared mixture to produce a colloidal suspension. The turbidity of the suspension was proportional to potassium concentration in the range of $2-7 \mathrm{mmol} / \mathrm{L}$. Test tubes were labelled accordingly i.e. standard, control, patient and blank. $10 \mathrm{~mL}$ of samples were pipettedinto respective tubes which were mixed and left at room temperature for three minutes after which the wavelength of the spectrophotometer was set to $500 \mathrm{~nm}$ and Zeroed with reagent blank and the absorbance of all tubes were read and recorded.

\section{Calculations}

Abs. of test $\times$ concentration of standard $=$ potassium concentration in $\mathrm{mmol} / \mathrm{L}$

Expected values: $3.4-5.3 \mathrm{mmol} / \mathrm{L}$.

\section{Bicarbonate $\left(\mathrm{HCO}_{3}^{-}\right)$estimation}

The $\mathrm{CO}_{2}$ reagent was prepared according to specification and tubes were labeled as blank, standard, controls, patients, etc. $1.0 \mathrm{~mL}$ carbon dioxide reagent was distributed into each tube and incubated at $37^{\circ} \mathrm{C}$ for three minutes. The wavelength of the Spectrophotometer was set at $340 \mathrm{~nm}$ and 5 $\mathrm{mL}$ of water, standard, and sample were pipetted into the cuvette labeled blank, standard, and patient respe for actively. The samples were mixed gently by inversion and incubated at $37^{\circ} \mathrm{C}$ for five minutes. Absorbance was read and recorded at 340 $\mathrm{nm}$ for all cuvettes.

\section{Calculations}

Abs. of blank - Abs. of sample Abs. of blank - Abs. of standard $\times$ concentration of standard $=\mathrm{CO} 2$ content of sample

Concentration of standard $=30 \mathrm{mmol} / \mathrm{L}$ Expected values: $23-34 \mathrm{mmol} / \mathrm{L}$

\section{Chloride estimation}

Test tubes were labeled accordingly i.e blank, calibrator, patient, etc. $1.5 \mathrm{~mL}$ chloride reagent was pipette into each tube. 10 $\mathrm{mL}$ of sample was added to the respective tubes and mixed. The samples were then incubated at room temperature for at least

Table 1. Variation in mean \pm standard deviation packed cell volume, plasma sodium $\left(\mathrm{Na}^{+}\right)$potassium $\left(\mathrm{K}^{+}\right)$bicarbonate $\left(\mathrm{HCO}_{3}{ }^{-}\right)$. Chloride $\left(\mathrm{Cl}^{-}\right)$, and glucose.

\begin{tabular}{lccccccc} 
Sulbjects & $\mathrm{N}$ & $\mathrm{PCV}(\%)$ & $\mathrm{Na}^{+}(\mathrm{mmol} / \mathrm{L})$ & $\mathrm{K}^{+}(\mathrm{mmol} / \mathrm{L})$ & $\mathrm{HCO}_{3}{ }^{-}(\mathrm{mmo} / \mathrm{L})$ & $\mathrm{Cl}-(\mathrm{mmo} / \mathrm{L})$ & $\mathrm{Glucose}(\mathrm{mg} / \mathrm{dL})$ \\
Test subjects & 50 & $30.04 \pm 5.31$ & $131.56 \pm 6.63$ & $3.93 \pm 79$ & $23.56 \pm 2.55$ & $99.52 \pm 7.44$ & $85.92 \pm 13.85$ \\
Control subjects & 50 & $38.74 \pm 3.12$ & $134.14 \pm 5.95$ & $3.62 \pm 0.51$ & $23.48 \pm 2.02$ & $99.50 \pm 6.33$ & $92.40 \pm 13.99$ \\
\hline T-test & & -11.540 & -2.149 & 2.330 & 0.190 & 0.096 & -2.904 \\
P-value & 0.001 & 0.037 & 0.024 & 0.850 & 0.924 & 0.006 \\
\hline
\end{tabular}


five minutes and a spectrophotometer was set to $480 \mathrm{~nm}$ and zeroed with a blank. Absorbance readings of all tubes were read and recorded.

\section{Calculations}

Abs. of unknown (test)

Abs. of calibrator

$\times$ concentration of calibrator $=$ concentration of chloride in $\mathrm{mmol} / \mathrm{L}$

\section{Glucose estimation}

Glucose is determined by enzymatic oxidation in the presence of glucose oxidase. The hydrogen peroxide formed reacts under catalysis of peroxidase, with phenol and 4-aminophenazone to form a red-violet quinonimine dye as an indicator. Test tubes were labeled accordingly i.e standard, sample, and blank. Pipette $2 \mathrm{~mL}$ of reagent into all tubes and $20 \mathrm{~mL}$ of standard and sample were added to respective tubes. These were mixed and incubated at $37^{\circ} \mathrm{C}$ for $10 \mathrm{~min}-$ utes. The absorbance (Abs) of the standard sample was measured against reagent blank within 60 minutes at $500 \mathrm{~nm}$ wavelength concentration of standard $99 \mathrm{mg} / \mathrm{dL}$.

\section{Calculations}

Abs. of sample

Abs. of standard

$\times 99=$ glucose concentration in $\mathrm{mmol} / \mathrm{L}$

Normal values: serum, plasma (fasting) 75.6-115.2 mg/dL

The electrolytes value were measured using SM23A spectrophotometer, (microfield instrument), England.

\section{Statistical analyses}

Data from the study was analyzed separately using paired $t$-test at $95 \%$ confidence interval, and analysis was done using the statistics package for social sciences (SPSS 13.0 for windows program). The results were presented as mean \pm standard deviation $( \pm \mathrm{SD})$ and P-values $<0.05$ were considered significant.

\section{Results}

Out of the fifty (50) subjects used during this study, $28(56 \%)$ had low parasites density; 13 (26\%) had moderate parasites density; while $9(18 \%)$ had a high density of malaria parasites (Figure 1).

The mean standard deviation of plasma sodium $\left(\mathrm{Na}^{+}\right)$, potassium $\left(\mathrm{K}^{+}\right)$, bicarbonate $\left(\mathrm{HCO}_{3}^{-}\right)$, chloride $\left(\mathrm{Cl}^{-}\right)$and glucose in infected subjects as well as the overall control subjects are shown in Table 1. The observed mean values of PCV (30.04 $\pm 5.31 \%) . \mathrm{Na}^{+}(131.56 \pm 6.63 \mathrm{mmol} / \mathrm{L})$, and glucose $(85.92 \pm 13.85 \mathrm{mg} / \mathrm{dL})$ in the malaria-infected subjects were significantly lower than the mean values obtained from the control subjects $(\mathrm{PCV}=38.743 .12 \%$; $\mathrm{Na}^{+}=134.14 \pm 5.95 \mathrm{mmol} / \mathrm{L}$, and glucose $=92.40 \pm 13.99 \mathrm{mg} / \mathrm{dL}) \quad(\mathrm{P}<0.05) . \quad$ A higher significant mean value of $\mathrm{K}^{+}$ $(3.93 \pm 0.79 \mathrm{mmol} / \mathrm{L})$ in the malaria-infected subjects compared with the control mean value of $\mathrm{K}^{+}(3.62 \pm 0.51 \mathrm{mmol} / \mathrm{L}$ was also observed $(\mathrm{t}=2.330 ; \mathrm{P}=0.023)$. The higher bicarbonate mean value obtained in the infected subjects, $\mathrm{HCO}_{3}^{-}(23.56 \pm 2.55$ $\mathrm{mmol} / \mathrm{L}$ ) compared with the lower value of $\mathrm{HCO}_{3}{ }^{-}(23.48 \pm 2.02 \mathrm{mmol} / \mathrm{L})$ was not statistically significant $(\mathrm{t}=0.190 ; \mathrm{P}=0.850)$. The mean value for chloride observed in the malaria-infected subjects, $\mathrm{Cl}^{-}(99.52 \pm 7.44)$ was higher than the observed mean in the control subjects. $\mathrm{Cl}^{-}(99.50 \pm 6.33)$, but was not statistically significant $(\mathrm{t}=0.096$; $\mathrm{P}=0.924)$.

In Table 2, the mean $( \pm \mathrm{SD})$ values of $\mathrm{PCV}, \mathrm{Na}^{+}, \mathrm{K}^{+}, \mathrm{HCO}_{3}^{-}, \mathrm{Cl}^{-}$and glucose in malaria patients of different age brackets

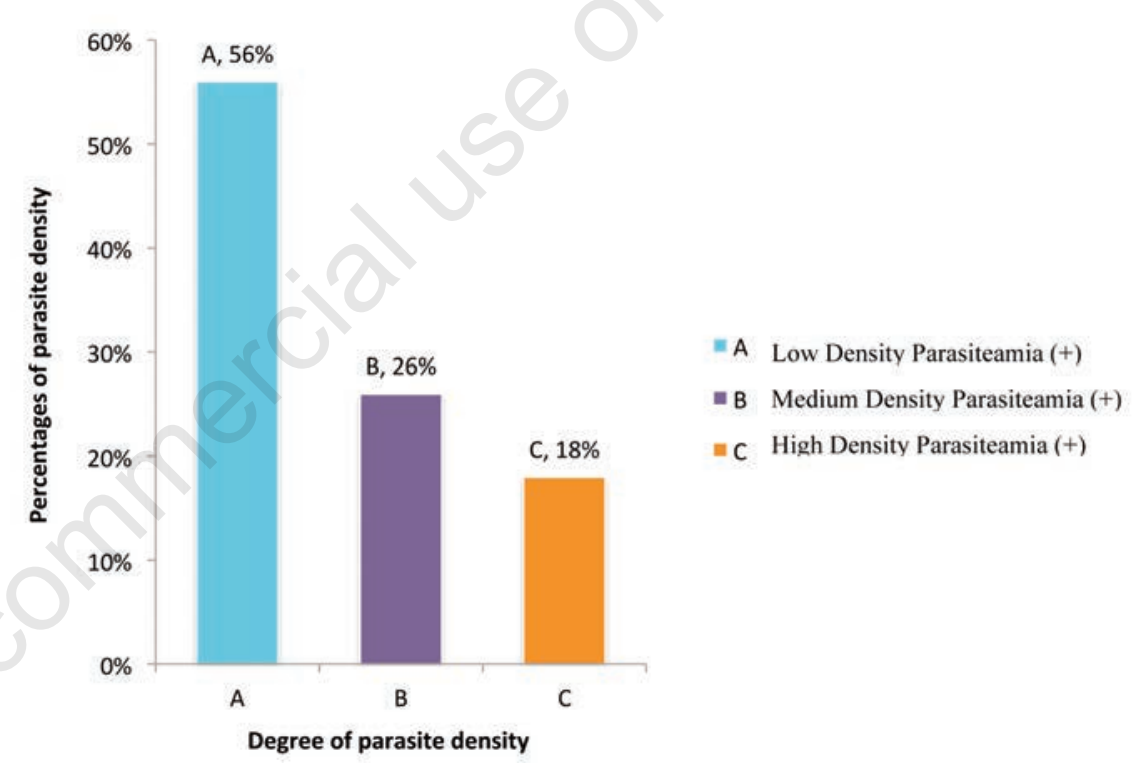

Figure 1. Degree of parasites density among infected subjects $(n=50)$.

Table 2. Comparison of mean \pm standard deviation packed cell volume, plasma sodium $\left(\mathrm{Na}^{+}\right)$potassium $\left(\mathrm{K}^{+}\right)$, bicarbonate $\left(\mathrm{HCO}_{3}{ }^{-}\right)$, chloride $\left(\mathrm{Cl}^{-}\right)$, and glucose levels of malaria patients and control subjects in the different age brackets.

\begin{tabular}{|c|c|c|c|c|c|c|c|}
\hline Age bracket, subjects & N. & PCV (\%) & $\mathrm{Na}^{+}(\mathrm{mmol} / \mathrm{L})$ & $\mathrm{K}^{+}(\mathrm{mmol} / \mathrm{L})$ & $\mathrm{HOC}_{3-}(\mathrm{mmol} / \mathrm{L})$ & $\mathrm{Cl}-(\mathrm{mmol} / \mathrm{l})$ & Glucose (mg/dL) \\
\hline \multicolumn{8}{|l|}{$1-20$ years } \\
\hline Test subjects & 12 & $26.20 \pm 3.13$ & $126.80 \pm 6.05$ & $3.50 \pm 0.66$ & $25.20 \pm 1.78$ & $100.80 \pm 10.20$ & $83.80 \pm 18.53$ \\
\hline Control subjects & 5 & $38.40 \pm 1.94$ & $129.80 \pm 7.46$ & $3.42 \pm 0.39$ & $22.00 \pm 2.54$ & $96.60 \pm 8.70$ & $85.60 \pm 14.04$ \\
\hline P-value & $\mathrm{P}<0.05$ & $P>0.05$ & $P>0.05$ & $P>0.05$ & $P>0.05$ & $P>0.05$ & $P>0.05$ \\
\hline \multicolumn{8}{|l|}{$21-40$ years } \\
\hline Test subjects & 31 & $30.25 \pm 6.28$ & $131.85 \pm 6.61$ & $3.81 \pm 0.72$ & $23.85 \pm 2.47$ & $100.20 \pm 7.58$ & \\
\hline Control subjects & 20 & $38.1 \pm 2.73$ & $134.95 \pm 5.36$ & $3.78 \pm 0.48$ & $23.50 \pm 1.76$ & $100.35 \pm 5.27$ & \\
\hline P-value & $\mathrm{P}<0.05$ & $\mathrm{P}<0.05$ & $P>0.05$ & $P>0.05$ & $P>0.05$ & $P>0.05$ & \\
\hline \multicolumn{8}{|l|}{$>40$ years } \\
\hline Test subjects & 6 & $29.66 \pm 4.03$ & $129.00 \pm 6.51$ & $4.11 \pm 0.54$ & $23.66 \pm 3.26$ & $100.66 \pm 7.08$ & $88.00 \pm 6.03$ \\
\hline Control subjects & 25 & $39.50 \pm 5.31$ & $130.16 \pm 5.63$ & $3.01 \pm 0.34$ & $24.50 \pm 2.07$ & $94.16 \pm 5.30$ & $102.16 \pm 15.84$ \\
\hline P-value & $\mathrm{P}<0.05$ & $P>0.05$ & $P>0.05$ & $P>0.05$ & $P>0.05$ & $P>0.05$ & $P>0.05$ \\
\hline
\end{tabular}


were compared statistically with the agematched controls, and there were significant differences $(\mathrm{P}<0.05)$ in the age brackets involving PCV only in the 1-20, 21-40 age brackets as well as both PCV and potassium in the $>40$ age brackets between the test subjects and their age-matched controls.

\section{Discussion}

The observed significantly lower packed cell volume (PCV), and higher potassium $\left(\mathrm{K}^{+}\right)$level in malaria-infected subjects than the control subjects can be attributed to the destruction of the erythrocytes by invading plasmodial parasite. The consequence is the lower hematocrit level and increases potassium level in the plasma due to the influx of this major intracellular cation from the intercellular to the extracellular fluid compartment. ${ }^{7-9}$ Red blood cells are the principal sites of infection in malaria. All the clinical manifestations are primarily due to the involvement of red blood cells. The growing parasites consume and degrade the intracellular proteins, mainly haemoglobin. The transport properties of the red cell membrane are altered. ${ }^{5}$ Massive destruction of red blood cells accounts for the rapid development of anemia especially in Plasmodium falciparum malaria since the parasitemia can be as high as $20-30 \%$ compared to other plasmodial species. ${ }^{5}$

The pathogenesis of anemia in malaria is extremely complex, multifactorial, and incompletely understood. It is thought to result from a combination of hemolysis of parasitized red blood cells accelerated the removal of both parasitized and innocently unparasitized red blood cells, depressed or ineffective erythropoiesis with dyserythropoietic changes. Other contributory factors may include decreased red cell deformability, splenic phagocytosis and/or pooling, so they have an increased rate of clearance from the circulation. ${ }^{10-12}$

Brooks et al. ${ }^{13}$ had reported the correlation of serum potassium, and the hemolysis of red blood cells in patients infected with malaria which agrees with the present study. According to the present study, a statistically lower plasma sodium level mean of $131.56 \pm 6.63$ against the mean control level of $134.14 \pm 5.955$ was observed. This can be attributed to vomiting and hemolysis in severe malaria conditions which raised plasma potassium level, thereby forcing more $\mathrm{Na}^{+}$back to the cell to maintain electrochemical neutrality. ${ }^{8}$ The observed higher mean chloride level in the test (99.62 \pm 7.44$)$, compared to the control value of $99.50 \pm 6.32$ was not understood, but according to Brain et al., ${ }^{7}$ the urinary concentration of chloride in Plasmodium falciparum infection is always low, possibly due to $\mathrm{Cl}^{-}$retention which may explain our findings.

The glucose level of malaria-infected subjects in this study was found to be lower than that of the normal control subjects. Zolg et al. and Sherman in their separate studies have linked this phenomenon to the fact that host glucose is the main energy source of asexual stages of Plasmodium falciparum, ${ }^{14,15}$ and that the most mature form of the parasite consumes up to 70 to 80 times the amount of glucose required by uninfected erythrocytes in vitro. The raised bicarbonate level in malaria-infected patients compared to the control subject was not understood, and may require further findings.

\section{Conclusions}

In conclusion, the observations of significant lower packed cells volume in of the subjects in the age group 1 to 20 is in line with observations of many workers that reported the age group to be vulnerable to anemia due to malaria infections, and therefore, should attract more curious attention by healthcare managers and researchers for improved level of care. This study, in essence, has affirmed several observations of previous workers of the effects of plasmodia malaria, especially the falciparum species on human red blood cells volume, plasma electrolytes, and glucose levels. The study draws further attention to the need to manage electrolyte derangements of severe malaria infections with clinical commitment.

\section{References}

1. Hay S, Guerra C, Tatem A, et al. The global distribution and population at risk of malaria: past, present and future.
Lancet Infect Dis 2004;4:327-36.

2. Cheesbrough M. Examination of blood for malaria parasites. Medical laboratory manual for tropical countries. 2nd Ed. Cambridge University Press; 1998. pp 240-244.

3. Warell DA, Molyneux ME, Beals PF. Severe and complicated malaria. Trans R Soc Trop Med Hyg 1990;12:1-65.

4. World Health Organization. Malaria. WHO fact sheet. 2016. Available from: http://www.who.int/mediacentre/factsheets/fs094/en/. Accessed: 04/10/2016.

5. Claire LM, James GB, Kelvin M. Clinical features and pathogenesis of severe malaria. Trends Parasitol 2004;20:597-603.

6. Barun DN, Whiter IT, Kee KE. A new short textbook of chemical pathology. 5th ed. London: Butlerend Tanner Ltd., 1998. pp 27-31.

7. Adams ARD, Maegraith BG. Clinical tropical diseases. 8th ed. Oxford: Blackwell Scientific Publications; 1984. pp 257-313.

8. Fortin A, Stevenson MM, Gross P. Susceptibility to malaria as a complex trait: big pressure from tiny creature. Hum Mol Genet 2002;11:2469-78.

9. J MacLeod. Davidson's principles and practice of medicine. 13th ed. Edinburgh: Churchill Livingstone; 1981.

10. Perrin LH, Mackey LJ, Miescher PA. The haematology of malaria in man. Sem Hematol 1982;19:70-81.

11. Clark JA, Chaudhri G. Tumor necrosis factor may contribute to the anemia of malaria by causing dyseythoposis. Br J Haematol 1988;70:99-103.

12. Angus SG, Hassan AW, Obi SO. The pattern of blood donation in North Eastern Nigeria. Nig J Surg Res 1991;1: 76-8.

13. Brooks MH, Malloy JP, Bartelloni PJ, et al. Pathophysiology of acute Falciparum malaria. I. Correlation of clinical and biochemical abnormalities. Am J Med 1967;43:735-44.

14. Zolg JW, Macleaod AJ, Scaife JG. The accumulation of lactic acid and its influence on the growth of plasmodium falciparum in synchronized cultures. In vitro 1984;20:205-15.

15. Sherman LW. Biochemistry of plasmodium (malaria parasites). Microbiol Rev 1983;43:435-94. 